\title{
Are the shoes appropriate to wear?: A study of cohort values
}

Received (in revised form): 29th January, 2008

\section{Paul M. Arsenault}

is an associate professor at the West Chester University in West Chester, Pennsylvania. He holds a PhD from Temple University, an MBA from the Babcock School of Management at Wake Forest University and a Masters in Psychology from Vanderbilt University. His undergraduate degree is from Marietta College. Dr Arsenault's research interests include generational/cohort differences, charismatic leadership, organisational change, managerial assessment and development.

\section{Michelle L. Patrick}

an associate professor at the West Chester University of Pennsylvania, earned her PhD in Marketing from Kent State University. Prior to earning her degree she held a variety of positions in market research firms. Her current research interest focuses on segmentation and service quality and how these factors influence a company's ability to extract value from its consumer base.

\section{Keywords segmentation, cohort analysis, Baby Boomer, age, consumer behaviour}

\begin{abstract}
This study investigates the values differences between and among cohorts by examining perceptions of the appropriateness of women wearing flip-flops in a formal situation. Results show there is a significant cohort difference in values and the level of appropriateness of the shoes worn in the formal situation with the President of the United States. Significant differences were found between the Veterans and the other younger cohorts. The major rationale for this is that the Baby Boomer influence on the two younger cohorts is very strong and enduring. Journal of Targeting, Measurement and Analysis for Marketing (2008) 16, 99-107. doi:10.1057/jt.2008.6; published online 17 March 2008
\end{abstract}

\section{INTRODUCTION}

The popularity of cohort analysis is very evident today. Newspapers and business journals often print articles about the differences in marketing towards cohorts. The reasons for this popularity, according to Glenn, ${ }^{1}$ are(1) the wealth of data available to refine market segmentation and(2) 'its usefulness in addressing substantive issues relating to aging and social and cultural change' (p. 1). The major reason for this situation, according to many people, has been the Baby Boomer cohort (born between 1945 and 1960) who through its sheer size and influence on the American culture

Correspondence: Paul M. Arsenault, 312 D Anderson Hall, West Chester University, West Chester, PA 19383, USA.

Tel: +1 (610) 436 2208;

Fax: + 1 (610) 4363458

E-mail: parsenault@wcupa.edu has transformed marketing and redefined concepts like work, retirement and family. ${ }^{2}$

Cohort effects ${ }^{3,4}$ have its roots in the sociological field. Mannheim used the term in the 1920s to explain political attitudes and behaviour of German youth, specifying a critical time period of ages 17-25 when people are most impressionable to social and political events. ${ }^{5}$ These events affected attitudes, beliefs and values that exert life-long influence. Ryder ${ }^{6}$ using historical movements such as the Protestant Reformation and the French Revolution as examples to support the contention that this conflict stems from young adults who are idealistic, critical of the adult world and therefore impelled by change. More recently, the definition of cohort effects has been transformed by marketers. They distinguish the difference as the effect of growing up during a specific time 
period versus an age effect that occurs due to maturation or chronological age. ${ }^{7}$ Therefore, cohort effects draw special attention to a shared or collective field of emotions, attitudes, preferences and dispositions and a set of embodied practices like leisure activities that each cohort uses to create its own traditions and cultures. ${ }^{8}$ Strauss and Howe ${ }^{9}$ in their seminal work add that given this effect, a cohort takes on a persona that includes attitudes, values and beliefs about family life, religion, gender roles and lifestyles. Meredith et al. ${ }^{5}$ add that these effects are highlighted by social events (ie September 11 and The Challenger incident) deemed 'defining moments' that are the glue that bind these cohorts and also differentiate them from other cohorts.

Validation of cohort differences has been accomplished by various studies. Schuman and Scott ${ }^{10}$ asked over 1,400 Americans(1) to think of national and world events and changes over the last 50 years that were especially important and(2) reasons why many people reported events and changes that occurred during their youth. Examples included reporting of World War II by people who were between the ages of 16 and 24 during the early 1940s and the Viet Nam conflict by people of the same age period in the 1960s and 1970s. The authors concluded that these important events/changes that occurred during these respondents' youth became an autobiographical memory that left an imprint in their long-term memory. These memories are related to future actions, Schuman and $\mathrm{Scott}^{10}$ state 'these deep personal feelings related to this event are a crucial element in the translation of experience into future action' (p. 379).

Further validation has been found through studies looking at nostalgia preferences. Holbrook and Schindler ${ }^{1-13}$ and Schindler and Holbrook $^{14,15}$ have found that people prefer the automobiles, music, fashion products and motion pictures that were popular during their youth due to nostalgia. Schindler and Holbrook ${ }^{15}$ conclude that many reputed differences by age are really differences by cohorts. Failing to recognise this effect could lead to faulty prediction and a lack of awareness of the impact of these effects on purchasing products like furniture and bicycles.

The use of cohort differences as a segmentation device has been used widely for years. One of the most well known users has been the automobile industry. Mercedes Benz's advertising campaign in the 1990s using Janis Joplin's song 'Oh Lord, Won't You Buy Me a Mercedes Benz?' to sell to Baby Boomers its new product line of automobiles $^{16}$ was very successful. More recently, automobile manufacturers are designing cars with more comfort and technologically advanced entertainment equipment for the Generation Xers (born between 1961 and 1980) because the members of this cohort dress casually and carry their entertainment with them. ${ }^{17}$ Chon ${ }^{18}$ reports that car manufacturers like Honda and Toyota are now successfully utilising a multi-cohort strategy with their products. Probably the most successful motor vehicle company has been HarleyDavidson, which has successfully targeted Baby Boomers by utilising their proclivity to stay young and their positive memories of the 1969 movie Easy Rider. Owing to this success, the median age of purchasing a motorcycle has risen from 24 in 1980 to 41 in 2003 with the median buyer of Harley-Davidson now being $47 .{ }^{19}$

The resurging interest in cohort analysis is derived from the impact of Baby Boomers on American economic structure and culture. The Baby Boomer cohort is roughly 78 million strong who came of age amid the 1960s, an era of cultural turmoil and drastic social change. ${ }^{20}$ The large number of Baby Boomers - 78 million has had a tremendous impact on the ageing of the American population. With the life expectancy age of 77.4 years, concerns about the long-term impact on the solvency of social security have arisen. Bernake, ${ }^{21}$ the chairman of the Federal Reserve Bank, states that Baby Boomers will severely test the current social security system because they will increase the number of people reaching retirement age over the next 25 years to 19 per cent of the US population up from 12 per cent today. This will change the ratio of Generation Xers and Nexters, paying for this group to retire, from 
five to one today to three to one 25 years from now. The biggest impact has probably been how Baby Boomers have changed the norms, attitudes and values in American culture. As Steinhorn ${ }^{20}$ states,

'the Baby Boomer said no (to the fact that every succeeding cohort should conform to previous cohorts norms and values), the Baby Boom refused to compromise its ideals, and in a span of a single cohort the Baby Boom has overturned decades if not centuries of outmoded norms, attitudes, and discriminatory practices, replacing them with a more fundamentally democratic culture.' (p. 16)

This new culture, Steinhorn goes on to state, embraced a new view on how to live life via freeing up individual expression, fighting for a healthier environment and annulling the shame of being different. Yankelovich ${ }^{22}$ adds that the Veterans fought World War II while the Baby Boomers fought a cultural war that unrepressed sexuality, promoted 'expressive individualism' and gave consumer choices.

The impact of Baby Boomers has created many opportunities in marketing. The Association of Retired People (AARP), in its effort to increase the membership, is capitalising on the fact that Baby Boomers are still buying the 1960s and 1970s music. To accomplish this, AARP began to sponsor concert tours of older musical artists and selling their music downloads on its website. ${ }^{23}$ Other examples include the reinvention of retirement homes, ${ }^{24}$ long-term care,${ }^{25}$ internet dating services, ${ }^{26}$ printing more large font type books ${ }^{27}$ and internet search engines. ${ }^{28}$ Even the influence of the Baby Boom cohort has been made a political issue in the 2008 presidential primary as candidate Barack Obama is branding himself as the voice of a Generation Xer (born between 1960 and 1980) to differentiate himself from Baby Boomer Hillary Rodham Clinton. ${ }^{29}$

Even with the increased acceptance of cohorts as a valuable tool in market segmentation, there is still concern over the importance of cohort effects. Leeds ${ }^{23}$ found little evidence of a generation gap in basic values. He stated, 'that even though younger people buy different CDs and clothes, they do not buy into a set of values different from their elders' (p. 50). Tolson ${ }^{30}$ argues that the hype around cohorts is obsessive and is 'a handy device for journalists to overplay the differences in order to have a more dramatic story' (p. 43). In reality, he believes there are more similarities than differences between cohorts. Deal ${ }^{28}$ adds that the cohort gap should be retired because people across cohorts have similar values and beliefs.

This empirical study is a two-part effort to increase the knowledge of cohort differences by investigating differences in values. Values are important to the knowledge base because values 'are the core beliefs or desires that guide or motivate attitudes and actions' (Osland et al., ${ }^{31}$ p. 136) of people. Kouzes and Posner ${ }^{32}$ go on to say that values inform us what to do or not to do as they are standards that guide our conduct in a variety of settings and situations.

The first part investigates value differences by cohorts utilising an instrument that has proven adequate in measuring these differences. ${ }^{33}$ The second part explores cohort difference in values as a guide in determining the appropriateness of shoes worn by a National Collegiate Athletic Association championship women's team in a formal photograph with the President of the United States in 2005. The photograph shows women (comprising women of the Nexter cohort, born after 1980) in the front row wearing sandals/flip-flops that raises the question are sandals/flip-flops appropriate to wear in this situation (see Figure 1). The incident prompted national television shows to interview both the women and their parents (probably either members of the Baby Boomer or Generation Xer cohorts) about whether a value difference existed around the appropriateness of the shoes. During one of these interviews, one of these women in the picture states, in defending their shoes, 'Nobody was wearing old beach flip-flops' and a mother of one of the women responded, 'Don't ask me about the flip-flops, it mortified me' (Associated Press, ${ }^{34}$ p. E2). Barrientos ${ }^{35}$ added that the incident was a reminder of the cohort dress code divide. This flip-flop incident has become the example/symbol for not how to dress professionally or be taken seriously in the workplace. 


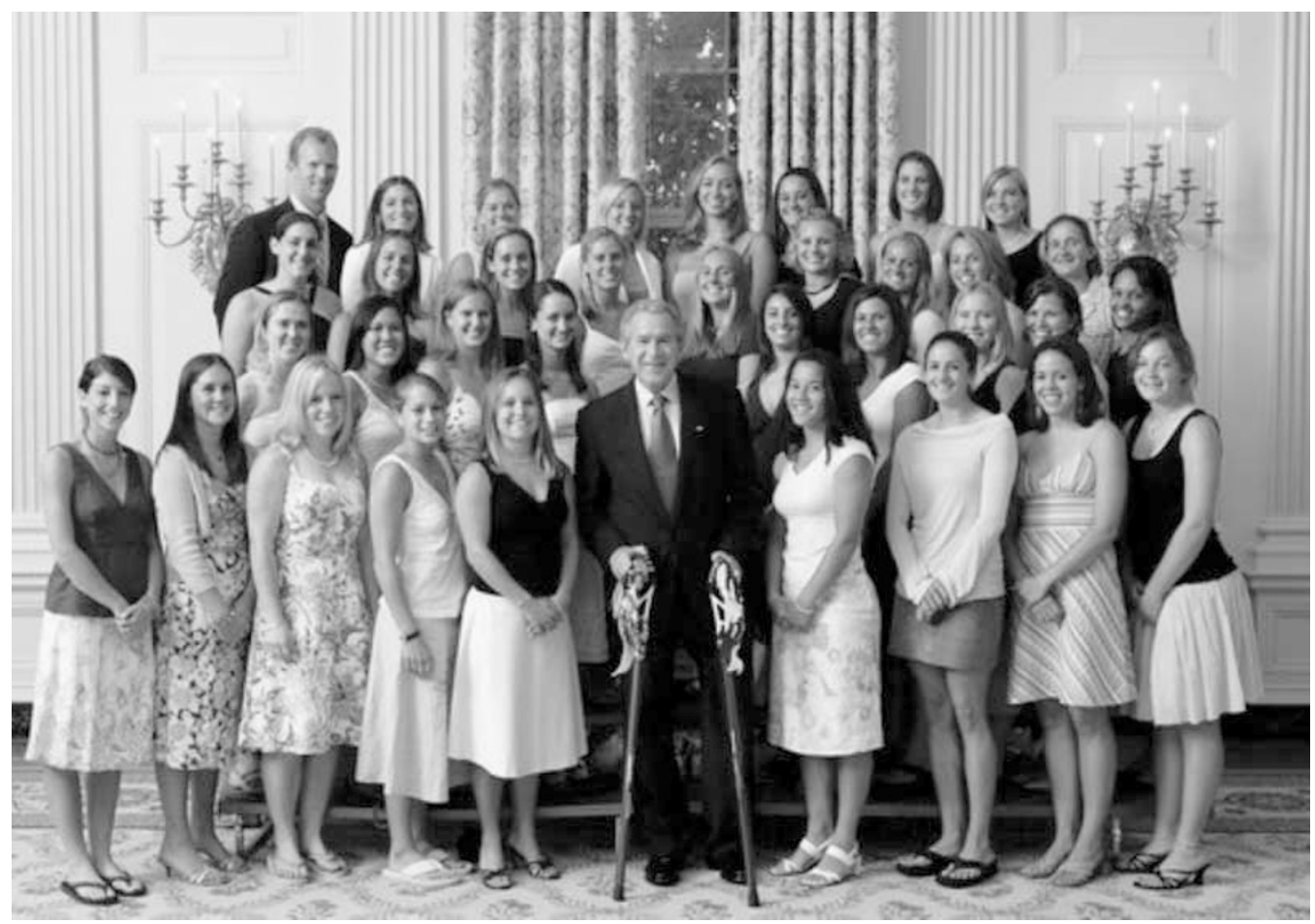

Figure 1: NCAA Championship Team with the President of the United States

\section{METHODOLOGY}

\section{Definition of cohorts}

Social scientists differ somewhat on how to name and segment cohorts. Smith and Clurman ${ }^{36}$ segment cohorts into three broad groups: (1) Matures, (2) Baby Boomers and (3) Generation X. Meredith and Schewe ${ }^{37}$ identify six cohorts ranging from the Depression cohort that came of age during a time of economic strife and increased unemployment, Baby Boomer cohorts I and II to Generation Y. This study utilised Zemke et al. ${ }^{38}$ generational cohort ${ }^{38,39}$ designations' (1) Veterans, (2) Baby Boomers, (3) Generation Xers and (4) Nexters (see Table 1 for general description of cohorts). The major reason for the use of Zemke et al.'s segmentation procedure is their addition of the Nexter cohort. This addition is important because of the differences between the Xers and Nexter cohorts. Generation Xers tend to be more skeptical about their future because they watched America fail militarily, politically, diplomatically and economically. ${ }^{38}$ Howe and Strauss ${ }^{40}$ add that the Generation Xers' skepticism originates from their attitude that these failures have charged them to clean up this mess without the resources. They have learned how to survive. Nexters are almost completely different in their viewpoints. Raised by Baby Boomers in a robust economy that has had significant technological and economic advancements, ${ }^{8}$ this cohort sees themselves as special as they were encouraged to follow their own interests and passions. ${ }^{41}$ This gave them the confidence to succeed and be positive about their future and find it easy to defer to authority. ${ }^{42}$

\section{Hypotheses}

The two hypotheses posed for this study are that there are no significant differences among cohorts (1) in values and (2) in the appropriateness of the shoes the women are wearing between cohorts.

\section{Instrument}

There were three components to the instrument. First, respondents were asked their gender and political party preference. The second component involved asking the respondents' about the most 
Table 1: A description of cohorts

\begin{tabular}{|c|c|c|c|}
\hline Cohort names & Birth years & Core values & Seminal events \\
\hline Veterans & $1922-1943$ & $\begin{array}{l}\text { Dedication, hard work, respect for } \\
\text { authority }\end{array}$ & $\begin{array}{l}\text { The Great Depression, World War II, } \\
\text { Lindbergh, FDR }\end{array}$ \\
\hline Baby Boomers & $1944-1960$ & $\begin{array}{l}\text { Optimism, personal gratification and } \\
\text { growth }\end{array}$ & JFK, civil rights and women's movements \\
\hline Generation Xers & $1961-1980$ & Diversity, technoliteracy, fun, informality & The Challenger Incident, AIDS, Rodney King \\
\hline Nexters & $1981-2000$ & $\begin{array}{l}\text { Optimism, civic duty, confidence, } \\
\text { achievement }\end{array}$ & Terrorism, Oklahoma city bombing, computers \\
\hline
\end{tabular}

Source: Adapted from R. Zemke, C. Raines and B. Filipczak, Generations at Work: Managing the Clash of Veterans, Boomers, Xers, and Nexters in Your Workplace, New York: AMACOM, 2000

Table 2: List of the 9 Rokeach values

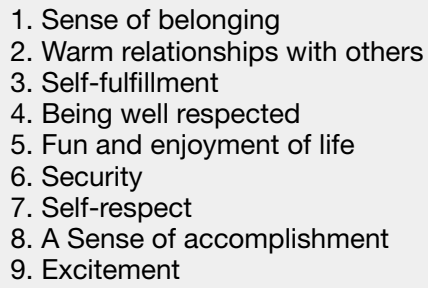

important values in their daily life via the Rokeach Value Survey (RVS). The RVS is a value instrument widely used by psychologists and marketers to understand what values are, what people value and what the purpose is of these values. $^{33}$

The RVS asks respondents to respond to nine value statements (see Table 2 for list of values) based on a 9-point degree of importance scale (from 1 designated as very unimportant to 9 designated as very important) and then give the one value that is most important in their daily life. The third component involved handing a copy of the photograph to the respondent with a statement explaining the context of the picture - giving the name of the team and why and when the picture was taken. Then, the interviewee was asked to evaluate the picture and respond to the following questions based on a 5 -point scale ranging from 1 being very inappropriate to 5 being very appropriate: the women's (1) overall appropriateness of dress, (2) hair, (3) facial makeup, (4) clothing and (5) shoes. The final question was whether the respondent had seen the photograph prior to the study to determine whether there was any bias by respondents who had seen the picture previously.

\section{Interviewers and respondents}

As used successfully in a previous study, ${ }^{43}$ interviewers were from an undergraduate marketing class in a mid-sized state university in the northeast. Each interviewer was asked to contact 12 individuals, three from each cohort as part of an assignment on cohort analysis.

Every participating student, before the actual interviewing, was given background in cohort analysis and experience in one-to-one interviewing. A week prior to the actual interviewing, the students read a chapter on the proper way to conduct one-to-one interviews. The guidelines were reviewed in class and students practiced interviewing each other.

The students were given the survey with three $5 \times 7$ colour copies of the photograph of the women's team with the President of the United States to use for each interview. Their instructions were to interview two males and two females from each of the four cohorts. The students were given one week to finish the interviews. The interviews were conducted in the fall of 2005 about four months after the publication of the photograph.

\section{RESULTS}

A total of 467 interviews were completed. The interviewers followed instructions well as there was an equal distribution among cohorts and gender. A republican political party preference comprised approximately 47 per cent of the total sample, followed by a democratic preference 
Table 3: Most important value by percentage to you in your daily live by cohort

\begin{tabular}{|c|c|c|c|}
\hline Veterans (\%) & Baby Boomers (\%) & Generation Xers (\%) & Nexters (\%) \\
\hline $\begin{array}{l}\text { Warm relationships with } \\
\text { people (26.1) }\end{array}$ & Self-respect (26.1) & $\begin{array}{l}\text { Fun and enjoyment with life } \\
(23.3)\end{array}$ & $\begin{array}{l}\text { Fun and enjoyment with life } \\
(30.2)\end{array}$ \\
\hline Security (15.7) & $\begin{array}{l}\text { Warm relationships with people } \\
\text { (23.5) }\end{array}$ & $\begin{array}{l}\text { A sense of accomplishment } \\
\text { (18.3) }\end{array}$ & $\begin{array}{l}\text { Warm relationships with } \\
\text { people (15.5) }\end{array}$ \\
\hline $\begin{array}{l}\text { A sense of accomplishment } \\
\text { (12.2) }\end{array}$ & $\begin{array}{l}\text { A sense of accomplishment } \\
(12.2)\end{array}$ & $\begin{array}{l}\text { Warm relationships with } \\
\text { people (15.0) }\end{array}$ & $\begin{array}{l}\text { A sense of accomplishment } \\
(13.8)\end{array}$ \\
\hline Self-fulfillment (11.3) & Self-fulfillment (8.7) & Self-respect (13.3) & Self-fulfillment (11.2) \\
\hline Being well respected (10.4) & Security (8.7) & Self-fulfillment (12.5) & Self-respect (10.3) \\
\hline $\begin{array}{l}\text { Fun and enjoyment with life } \\
(10.4)\end{array}$ & Fun and Enjoyment with life (8.7) & Security (7.5) & Excitement (7.8) \\
\hline Self-respect 7.8 & Being well respected (6.1) & Being well respected (4.2) & Being well respected (4.3) \\
\hline Sense of belonging (5.2) & Sense of belonging (6.1) & Excitement (3.3) & Sense of belonging (3.4) \\
\hline Excitement $(0.0)$ & Excitement $(0.0)$ & Sense of belonging (1.7) & Security (3.4) \\
\hline
\end{tabular}

(37.8 per cent) and an independent preference (12.4 per cent). Only approximately 20 per cent of the respondents had seen the picture before.

On average all cohorts stated that the shoes in the photograph were somewhat inappropriate. The overall mean was 2.49 (with 1 being very inappropriate and 5 being very appropriate) with Veterans having lowest mean or being less appropriate $(\mathrm{M}=2.15)$, followed by the higher means of the Baby Boomers, Generation Xers and Nexters $(\mathrm{M}=2.48,2.48$ and 2.75, respectively). The overall mean of whether their dress was appropriate was higher $(M=2.69)$ but still somewhat inappropriate, while the other questions about the women's appearance were fine $(M=3.41$ for clothing, $M=3.98$ for facial makeup and $M=3.94$ for hair).

The results support both significant differences and similarities between the cohorts. An ANOVA was conducted for the nine values to determine the effect of the cohorts. Out of the nine values, there was a significant difference in seven of them. Only the values sense of belonging and self-fulfillment were not significant.

The significant differences are found between (1) Baby Boomers and the other cohorts, (2) Veterans and Baby Boomers and two younger cohorts, and (3) Nexters and the older cohorts. Using the Tukey HSD for all comparisons, the test reveals that Baby Boomers mean ranking $(\mathrm{M}=8.60)$ for self-respect is significantly $(\mathrm{p}<0.05)$ higher in importance than Generation Xers $(M=8.22)$ and Nexters $(M=8.15)$. Also,
Baby Boomers have a significant mean ranking $(M=8.37)$ than Veterans $(M=7.83)$ for sense of accomplishment. The same significance is found for the value of security as Baby Boomers and Veterans ( $M=8.59$ and 8.38 , respectively) have significantly $(p>0.05)$ higher means than the Nexters $(M=7.47)$. With almost identical mean ranking for warm relationships with others, Baby Boomers $(M=8.15)$ and Veterans $(M=8.14)$ have significantly $(p>0.05)$ higher means than Generation Xers $(M=7.67)$.

For the values of fun and enjoyment with others and excitement, there was a reversal in which cohorts had significantly higher means. Nexters had significant $(p>0.05)$ higher means using the Tukey HSD test than the other three cohorts for excitement and fun and enjoyment, and significant lower means for the values warm relationships with others and security. Nexters' means for excitement and fun and enjoyment with others $(M=7.70$ and 8.26$)$ were significantly $(p>0.05)$ higher than the means for the Veterans $(M=6.18$ and 7.70), Baby Boomers $(M=6.51$ and 7.63) and Generation Xers $(M=7.00$ and 7.71, respectively).

In choosing the most important value in their daily life, there were both differences and similarities between cohorts (see Table 3). The differences were highlighted by the cohort's most important value. Veterans overwhelmingly chose warm relationships with people while Baby Boomers stated that self-respect was most important. Generation Xers and especially Nexters chose fun and enjoyment of life as their 
Table 4: Summary for variables predicting is their shoes appropriate?

\begin{tabular}{lrll}
\hline Variable & B & SE B & \multicolumn{1}{l}{ B } \\
\hline Cohort & 0.142 & 0.054 & $0.123^{\star *}$ \\
Gender & -0.192 & 0.120 & -0.004 \\
Political & -0.192 & 0.120 & -0.074 \\
$\begin{array}{c}\text { preference } \\
\text { Constant }\end{array}$ & 2.446 & 0.277 & \\
\hline${ }^{\star \star} p<0.01$. & & &
\end{tabular}

Table 5: Is their shoes appropriate by cohort and gender means

\begin{tabular}{llll}
\hline Cohort & Overall $(\mathbf{X})$ & Female $(\mathbf{X})$ & Male $(\mathbf{X})$ \\
\hline Veterans & $2.15^{\star}$ & $1.95^{\star *}$ & 2.53 \\
Baby Boomers & 2.48 & 2.56 & 2.36 \\
Generation & 2.48 & 2.37 & 2.60 \\
$\quad$ Xers & 2.75 & 2.73 & 2.76 \\
Nexters & & & \\
\hline
\end{tabular}

${ }^{*} p<0.05 ;{ }^{* *} p<0.01$.

most important value in their daily lives. Another important difference was the security value that was the second highest chosen value by Veterans but much less chosen as their most important daily value by the other three cohorts. Similarities are highlighted by the values warm relationships with people as important along with sense of accomplishment as one of their most preferred choices.

For the second hypotheses of whether the shoes that the women were wearing were appropriate or not, there were two analyses completed. A multiple regression was run to determine whether any of the independent variables (political party, gender and cohort) were significant predictors. Table 4 shows the results with cohort being the only variable to have significant $(p<0.01)$ weight. Therefore, the second hypothesis is rejected indicating that there is a cohort difference in whether the shoes were appropriate.

The second analysis was to determine where the significant differences were between cohorts. Table 5 shows the means (with 1 being very inappropriate and 5 being very appropriate) by cohort and gender. An ANOVA with the covariates political party preference, and whether the respondent saw the picture, found that there was a significant $(p>0.05)$ difference between the Veterans and the other three cohorts. Upon further investigation, the significant differences were found among females from each cohort (see Table 5). Veteran females $(M=1.94)$ were significantly $(p<0.01)$ more likely to find the shoes inappropriate than the females from the other three cohorts $(M=2.37,2.56$ and 2.73, respectively). Baby Boomers and Generation Xers had the same overall means except Baby Boomer males stated that the shoes were more inappropriate than Baby Boomer females and the Nexters males' and females' means were almost identical.

\section{DISCUSSION}

The results show a cohort effect in values and whether the shoes the women were wearing were appropriate. The values of self-respect and a sense of accomplishment, which are significantly higher for Baby Boomers, are ones that Strauss and Howe, ${ }^{9}$ Yankelovich ${ }^{22}$ and Steinhorn ${ }^{20}$ state are truly important to Baby Boomers. This is because Baby Boomers are very interested in personal and social self-expressiveness, more control of their lives and accomplishment both personally and materialistically. ${ }^{22,5}$

The significance of having a warm relationship with others as a key cohort value for Generation Xers is another cohort effect that marketers need to be sensitive to when targeting cohorts. Generation Xers' need for warm relationships stem from the divorce trend that was part of their life experience. They looked to friends for emotional support in their childhood and early adult years. Yankelovich ${ }^{22}$ states that this cohort effect has led to a major trend in society of people wanting deeper personal relationships, one that is hungry for community and being more humane.

Nexters' higher significant means from the other three cohorts' values excitement and fun and enjoyment for others and lower significant mean for security may be more of an age than a cohort effect. One reason is that Nexters responding to the survey could not be more than 25 , so given cohort theory, they really have not been given the time to establish a persona that 
includes attitudes, values and beliefs focused on defining moments. As Schewe and Meredith ${ }^{44}$ state, they are still a work in progress. This was supported by a study where Nexters' responses versus older cohorts in listing their favourite movies, leaders and most influential events in their lives were very inconsistent while the older cohorts had more consistent responses. ${ }^{43}$ The second reason is that the values of fun, enjoyment and excitement are more important to young people as they are of the age when people traditionally challenge life, search for new experiences and find change important in their lives. They fit the experiencer type of Value Attitude and Lifestyle Survey. Experiencers seek stimulation, are active and appreciate the unconventional while Generation Xers and Baby Boomers are more likely to be achievers and thinker types, more goal-oriented and satisfied with their lives. ${ }^{7}$

The cohort effect on the appropriateness of the shoes the women were wearing is a great indicator of the strong influence of Baby Boomers' on the values on younger cohorts. In longitudinal surveys over the last 30 years, there is virtually no cohort gap between Boomers and their kids, nothing close to the cohort chasm that separated Boomers and the Veterans. ${ }^{20}$ In support, Mitchell ${ }^{45}$ found that 94 per cent of the two younger cohorts share their parents' value as they think their parents (mostly Baby Boomers) are cool. Therefore, the importance of Baby Boomers' values on their own cohort and younger cohorts should be in the forefront of marketers' perspectives in segmentation rather than thinking that there are significant differences between these cohorts.

The similarities found in the results between cohorts are important, too, for marketing programmes. This allows marketers to use a common language ${ }^{32}$ in communicating to consumers and prevents them from making sweeping stereotypical assumptions or decisions about differences in cohorts. $^{28}$

The question of whether there was a cohort dress divide in the appropriateness of the women's shoes is important. Even though the majority of the participants thought the shoes were inappropriate, Veterans, a cohort known for its deference to corporate culture mentality and conformity, thought that the women's shoes were significantly less appropriate than the other cohorts. But for the other three cohorts the results indicate that the Baby Boomer values of less conformity and more casualness are embraced. This is especially shown by females. Veteran women's more inappropriate significant mean indicates Veteran's more deference to formality. This contradicts the Generation Xers and Nexters' females who are more in-tuned with Baby Boomer women who took a strong stand against the Veteran's view of women roles.

Females of the Baby Boomer, Generation Xers and Nexter cohorts therefore view dress as one important way to express their individualism.

This study provides evidence that cohort segmentation has utility but with a different perspective. This change of perspective is the influence of the Baby Boomer cohort on the younger cohorts. More research needs to be carried out to show the Baby Boomer's influence but given the results of this study marketers have to be more aware of this factor.

In addition, caution needs to be taken with cohort effects. As Schewe and Meredith ${ }^{44}$ state, a cohort effect is very useful in marketing and promoting products but clearly all values, attitudes and behaviour are not cohort driven. Other factors such as age, economic differences and that people are as similar as they are different have to be taken into consideration. There is definitely a need to take a more holistic approach in market segmentation. $^{2}$ The over-hyping of cohort differences many times illustrated in the media should be avoided.

Finally, further research is needed to address the measurement of these cohorts and how to clearly separate a cohort effect from an age effect especially with groups that are young and have not had time to develop their own cohort persona.

\section{References}

1 Glenn, N. D. (2005) 'Cohort Analysis', 2nd edn, Sage Publications, Thousand Oaks, CA.

2 Sokota, K. (2006) 'A holistic approach to marketing to baby boomers', MarketingProfs.com., retrieved 18th July, 2006 from http://marketingprofs.com. 
3 Markides $^{4}$ differentiates cohort effects from age and period effects. Whereas, cohort effects relate to the essence of social change, age effects are associated with the biological process of ageing internal to individuals. Period effects are due to major historical events such as world wars or an economic crisis.

4 Markides, K. S. (2006) 'Encyclopedia of Health and Aging', Sage Publications, London.

5 Meredith, G., Schewe, C. D. and Hiam, A. (2002) 'Managing by Defining Moments', Hungry Minds, New York.

6 Ryder, N. B. (1965) 'The cohort as a concept in the study of social change', American Sociological Review, Vol. 30, pp. 843-861.

7 Schiffman, L.G. and Kanuk, L.L. (2007) 'Consumer Behavior', Prentice-Hall, New York.

8 Schewe, C. D. and Evans, S. M. (2000) 'Market segmentation by cohorts: The value and validity of cohorts in American and abroad', Journal of Marketing Management, Vol. 16, pp. 129-142.

9 Strauss, W. and Howe, N. (1997) 'The Fourth Turning', Broadway Books, New York.

10 Schuman, H. and Scott, J. (1989) 'Generations and collective memories', American Sociological Review, Vol. 54, pp. 359-381.

11 Holbrook, M. B. and Schindler, R. M. (1994) 'Age, sex, attitude toward the past as predictors of consumer' aesthetics tastes for cultural products', Journal of Marketing Research, Vol. 31, pp. $412-422$.

12 Holbrook, M. B. and Schindler, R. M. (1993) 'Critical periods in the development of men's \& woman's tastes in personal appearances', Psychology and Marketing, Vol. 10, pp. 549-564.

13 Holbrook, M. B. and Schindler, R. M. (1989) 'Some exploratory findings on the development of musical tastes', Journal of Consumer Research, Vol. 16, pp. 119-124.

14 Schindler, R. M. and Holbrook, M. B. (1996) 'Market segmentation based on age and attitude toward the past: Concepts, methods, and findings concerning nostalgic influences on customer tastes', Journal of Business Research, Vol. 37, pp. 27-39.

15 Schindler, R. M. and Holbrook, M. B. (1993) 'Critical periods in the development of men's and women's tastes in personal appearance', Psychology \& Marketing, Vol. 10, pp. 549-564.

16 Rice, F. and McDonald, K. S. (1995) 'Making generational marketing come of age', Fortune, Vol. 131, pp. 110-114.

17 Freeman, S. (2002) 'Car makers get creative appeal to generation y', Wall Street Journal, 14th January, pp. B1-B4.

18 Chon, G. (2006) 'Car makers court two generations', The Wall Street Journal, 9th May, pp. B1, B3.

19 Caldwell, C. (2006) 'Geezery rider: Why is a symbol of youth rebellion having a senor moment?' New York Times Magazine, 29th October, pp. 11-12.

20 Steinhorn, L. (2006) 'The Greater Generation: In Defense of the Baby Boom Legacy', St. Martins Press, New York.

21 Bernanke, B. S. (2007) 'Bernanke's prepared text', Wall Street Journal, 18th January, p. A2.

22 Yankelovich, D. (1998) 'The shifting direction of America's cultural values', Address to DYG's Annual Scan Conference, 29th May.

23 Leeds, J. (2006) 'Rock of ages', New York Times, Retrieved 26th November, 2006, from http://nytimes.com.

24 Heavens, A. J. (2006) 'A rise is seen in the 55-plus home market', Philadelphia Inquirer, 12th November, pp. J1, J13.
25 Blumenstock, C. (2006) 'Baby boomers are reinventing longterm care', Nursing Homes: Long Term Care Management, Vol. 55, pp. $22-24$.

26 Silver, S. (2007) 'How match.com found love among boomers: Dating site prospers targeting older singles; The body art question', The Wall Street Journal, 27th January, pp. A1, A12.

27 Vann, K. (2007) 'Publishers cater to baby boomers with largetype books', Hartford Courant. 31st May, Retrieved 14th June, 2007 from http://www.courant.com.

28 Delaney, K. (2007) 'Web search engine bucks status quo by seeking results for baby boomers', Wall Street Journal, 17th January, p. D5.

29 Broader, J. M. (2007) 'Shushing the baby boomers', The New York Times, 21st January, Retrieved 22nd January, 2007 from http:// nytimes.com.

30 Tolosn, J. (2001) 'Is generation a bad word?' US News and World Report, 13th August, pp. 42-43.

31 Osland, J. S., Kolb, D. A., Rubin, I. M. and Turner, M. E. (2007) 'Organizational Behavior: An Experiential Approach', 8th edn, Prentice-Hall, Upper Saddle River, NJ.

32 Kouzes, J. M. and Posner, B. Z. (2003) 'Credibility; How Leaders Gain and Lose it, Why People Demand it', Jossey-Bass, San Francisco.

33 Johnston, C. S. (1995) 'The Rokeach value survey: Underlying structure and multidimensional scaling', The Journal of Psychology, Vol. 5, pp. 583-597.

34 Associated Press (2005) 'After a big victory, agony of the feet', Philadelphia Inquirer, 20th July, p. E2.

35 Barrientos, T. (2005) 'Flip-flop madness', Philadelphia Inquirer, 12th July, p. E1.

36 Smith, J. W. and Clurman, A. (1997) 'Rocking the Ages', Harper Business Press, New York.

37 Schewe, C. D. and Meredith, G. E. (1994) 'Digging deep to delight the mature adult consumer', Marketing Management, Vol. 3, pp. 20-35.

38 Zemke, R., Raines, C. and Filipczak, B. (2000) 'Generations at Work: Managing the Clash of Veterans. Boomers, Xers, and Nexers in Your Workplace', AMACOM, New York.

39 Zemke, Raines, and Filipczak ${ }^{38}$ use the term generational cohort which is very similar to the cohort definition used in this study. Their definition of a generational cohort is as a combination of coincidence of birth, common tastes, attitudes and experiences that develop their own unique personalities which is very similar to the cohort definition used in this study.

40 Howe, N. and Strauss, B. (1993) '13th Gen: Abort, Retry, Ignore, Fail?', Vintage Books, New York.

41 Outlaw Consulting (2003) 'How the y's are different?: Shifting gender roles among 20-26 year olds', Retrieved 12th June, 2007 from http://www.outlawconsulting.com.

42 Brooks, D. (2001) 'The organization kid', The Atlantic Monthly (April), pp. 40-54.

43 Arsenault, P. (2004) 'Validating generational differences: A legitimate diversity and leadership issue', Leadership \& Organization Development Journal, Vol. 25, pp. 124-141.

44 Schewe, C. D. and Meredith, G. E. (2001) 'Segmenting the market by cohorts: Age really matters-"Coming of age" that is', in Macchinte, R. (ed), 'Taking Sides: Marketing', McGaw-Hill, New York.

45 Mitchell, S. (1995) 'The next baby boom', American Demographics, Vol. 17, pp. 22-30. 